\title{
Measuring Anterior Chamber Inflammation After Cataract Surgery: A Review of the Literature Focusing on the Correlation with Cystoid Macular Edema
}

This article was published in the following Dove Press journal:

Clinical Ophthalmology

\author{
Michele De Maria (iD) ${ }^{1,2}$ \\ Danilo lannetta' \\ Luca Cimino ${ }^{3}$ \\ Marco Coassin ${ }^{4}$ \\ Luigi Fontana (D) \\ 'Ophthalmology Unit, AUSL-IRCCS of \\ Reggio Emilia, Reggio Emilia, Italy; \\ ${ }^{2}$ Clinical and Experimental Medicine \\ Ph.D. Programme, University of Modena \\ and Reggio Emilia, Modena, Italy; ${ }^{3}$ Ocular \\ Immunology Unit, Azienda USL-IRCCS di \\ Reggio Emilia, Reggio Emilia, Italy; \\ ${ }^{4}$ Ophthalmology, University Campus Bio- \\ Medico of Rome, Rome, Italy
}

\begin{abstract}
Cystoid macular edema (CME) is an infrequent, though potentially visually impairing, complication after uneventful cataract surgery. Rupture of the blood-aqueous barrier, with leakage of serum proteins into the aqueous humour, is the main pathogenic factor. However, only a few studies investigated the potential correlation between anterior chamber (AC) inflammation and the risk of cystoid macular changes occurring after surgery. This review aims to identify evidence of a correlation between AC inflammation and the risk of pseudophakic CME. One hundred eighty-seven prospective trials investigating AC inflammation after uncomplicated cataract surgery were identified. Methods of analysis of AC inflammation and the frequency of macular changes were recorded. In the majority (51\%) of the studies, inflammation was assessed by clinical grading, followed by laser flare and cell photometry (LFCP) (42\%) and aqueous humour sample (4\%). Few studies (4\%) adopted a combined LFCP and aqueous sample or clinical grading analysis. Sixteen (9\%) studies investigated AC inflammation and macular changes by OCT (7\%) or fluorescein angiography (2\%). Correlation between the amount of postoperative AC inflammation and frequency of CME was documented in 7 studies, not confirmed in 2 studies, and not examined in the other 7. LFCP, more than the other methods of analysis, correlated with the frequency of CME postoperatively. Investigation of the relationship between $\mathrm{AC}$ inflammation and the risk of CME changes requires the adoption of quantitative methods of analysis of the inflammatory response after surgery. For this purpose, due to the low level of inflammation in the AC after uncomplicated cataract surgery, LFCP, more than subjective clinical grading, seems a more sensitive and reproducible method of measurement. Inflammation assessment after cataract surgery has a potential role in predicting the risk of CME development and may help to titrate the duration and intensity of treatment in relation to the surgical inflammatory response.
\end{abstract}

Keywords: anterior chamber inflammation, cataract surgery, clinical grading, laser flare photometry, anterior segment optical coherence tomography, aqueous humour sample, cystoid macular edema

\section{Introduction}

Cataract surgery is the most frequently performed procedure in many developed countries. ${ }^{1}$ The technique is continuously evolving to meet the goals of patients and surgeons, having reached a level of refinement to be considered one of the most successful treatments in medicine. ${ }^{2}$ Despite the high level of safety of modern
Correspondence: Luigi Fontana Ophthalmology Unit, AUSL-IRCCS of Reggio Emilia, Viale Risorgimento 80 , Reggio Emilia 42I22, Italy

Email luifonta@gmail.com 
phacoemulsification, pseudophakic cystoid macular edema (CME) remains a frequent cause of unfavourable visual outcomes that may occur after uncomplicated surgery. ${ }^{3,4}$ By definition, CME is a thickening of the macula due to leakage and accumulation of fluid in the intracellular spaces, causing blurred or decreased vision. Systemic diseases (diabetes, ${ }^{5-8}$ hypertension ${ }^{8}$ ), intraoperative complications (posterior capsule rupture ${ }^{7}$ with or without vitreous loss, ${ }^{8}$ iris trauma ${ }^{9}$ ), and pre-existing ocular conditions (uveitis, ${ }^{7,10}$ diabetic retinopathy, ${ }^{11}$ history of vein occlusion, ${ }^{11}$ macular epiretinal membranes, ${ }^{11}$ previous retinal detachment, ${ }^{7}$ pseudoexofliation ${ }^{12}$ ) increase the risk of pseudophakic CME development. Alongside these predisposing factors, angiographic signs of CME after cataract surgery are reported up to $70 \%$ in some studies. ${ }^{7,8}$ More specifically, the incidence of subclinical pseudophakic CME, diagnosed by optical coherence tomography (OCT), varies between 4 and $10.9 \%,{ }^{10,13,14}$ while clinically significant CME, with transient or permanent visual impairment, ranges from $1 \%$ to $4 \%$ according to various studies. ${ }^{7,10,11}$

The exact pathogenesis of CME after cataract surgery remains unclear. Surgical trauma causes blood-aqueous barrier disruption with leakage of pro-inflammatory molecules and cells in the anterior chamber (AC). ${ }^{15}$ Prostaglandins and other pro-inflammatory mediators, released by the anterior uvea, diffuse into the vitreous and increase the permeability of perifoveal capillaries, resulting in the intraretinal fluid accumulation with cystoid changes of the retinal layers. ${ }^{16}$

To date, the risk of CME, based on the amount of postsurgical inflammation, remains uncertain, as only a few studies in the literature have attempted to correlate the degree of intraocular inflammation to the risk of CME development after cataract surgery. The majority of the studies focused on the anti-inflammatory effect of ophthalmic steroids and non-steroidal anti-inflammatory drugs for preventing or treating of $\mathrm{CME}$, principally measuring macular changes after surgery, more than accurately assessing the AC inflammatory response.

Routinely, clinicians evaluate the level of AC inflammation by grading cells and flare at the slit lamp according to the Standardized Uveitis Nomenclature (SUN). ${ }^{17}$ Compared to uveitis, inflammation after uncomplicated cataract surgery is generally low. Therefore, SUN grading may present some limitations due to its qualitative assessment. Lately, new technologies have been developed to quantify AC inflammation objectively. Laser flare and cell photometry (LFCP) ${ }^{18}$ and, more recently, anterior segment optical coherence tomography (AS-OCT)19, have arisen popularity and consensus among specialists in order to quantitatively define inflammation and to obtain objective measurements on its course and therapy response. Moreover, molecular biology and modern methods of aqueous humour samples analysis ${ }^{19}$ allow clinicians to titrate inflammatory mediators involved in this process.

This literature review focuses on the results of studies that evaluated $\mathrm{AC}$ inflammation after uneventful cataract surgery, aiming to identify evidence of a correlation between quantitative measurements of $\mathrm{AC}$ inflammation and the risk of CME development. Strengths and weaknesses of each technique used to evaluate AC inflammation will be discussed. Finally, the rationale of their choice and use in the field of research and routine clinical practice will be further addressed.

\section{Method of Literature Search}

We searched the PubMed database (1949-2019) and Ovid Medline (1946-2018) for peer-reviewed publications relevant to the topic of AC inflammation after cataract surgery starting from 1989. The year 1989 was chosen as it is when the first generation of an LFCP was commercialized. Keywords included: cataract surgery, cystoid macular edema, AC inflammation, laser flare and cells photometry, anterior segment optical coherence tomography (AS-OCT) and aqueous sample. We did not use any language restriction in the electronic searches. Data were extracted from the full-texts of the articles considered. For non-English articles, the provided English abstracts were examined in advance for eligibility before to extrapolate data from the full paper. The last electronic search was conducted in September 2019. We selected only prospective studies on uneventful cataract surgery by using the dedicated research tool on the PubMed web site. Experimental animal models, in vitro studies, reviews, and case reports or case series were excluded. Only papers in which one of the primary or secondary outcomes were the assessment of AC inflammation were included.

Data from the included studies were compiled in a Microsoft Excel Database (Version 16.16.14, 2018 Microsoft, Washington, USA). Information extracted and analyzed were:

- The title, authors, publication years, journal;

- Sample size;

- Research Field;

- Follow-up; 
- The test used to assess AC inflammation: clinical grading (SUN), LFCP, AS-OCT, aqueous sample analysis;

- The examination used to assess CME: fluorescein angiography or OCT;

- Correlation between $\mathrm{AC}$ inflammation and $\mathrm{CME}$, if present.

\section{Results}

The literature search retrieved 187 titles of full-length articles. The full-text of the papers was reviewed by two authors (MDM and LF) to check for adherence to the topic under investigation. We identified ninety-five papers $(51 \%)$ that measured inflammation by clinical grading, $78(42 \%)$ that used LFCP, and $7(3 \%)$ that analyzed aqueous samples. We found no studies that employed AS-OCT to assess inflammation after cataract surgery. Moreover, we included two (1\%) studies reporting a combined analysis of AC inflammation using LFCP with aqueous humour sampling and $5(3 \%)$ papers reporting the use of both LFCP and SUN grading.

Sixteen $(9 \%)$ studies searched for evidence of macular changes after surgery, 12 (6\%) using OCT, 3 (2\%) using fluorescein angiography, and $1(1 \%)$ aqueous humour sampling. Among these, 7 papers identified a positive correlation between the degree of $\mathrm{AC}$ inflammation and the frequency of postoperative macular edema. In contrast, 2 papers did not confirm this association, and 7 studies did not attempt this analysis. ${ }^{12,20-34}$ Study characteristics and results are summarized in Figure 1.

\section{Discussion Clinical Grading}

Slit-lamp examination is a commonly used technique to detect and grade AC inflammation in routine clinical practice. The herein review showed that the SUN scoring system is the most employed method of inflammation assessment in clinical trials conducted on cataract surgery. However, none of the studies in this group attempted to correlate AC inflammatory score to the macular changes that occurred postoperatively (Table 1).

The SUN clinical grading is a highly effective method to assess inflammation in routine clinical practice. In the field of uveitis, it allows clinicians to score visible inflammation rapidly and to titrate clinical decisions according to the variations of flare and cells present in the AC. ${ }^{17}$ In contrast, we believe that the SUN may fail to provide a precise assessment of low grades of inflammation occurring after uncomplicated phacoemulsification. The inflammatory

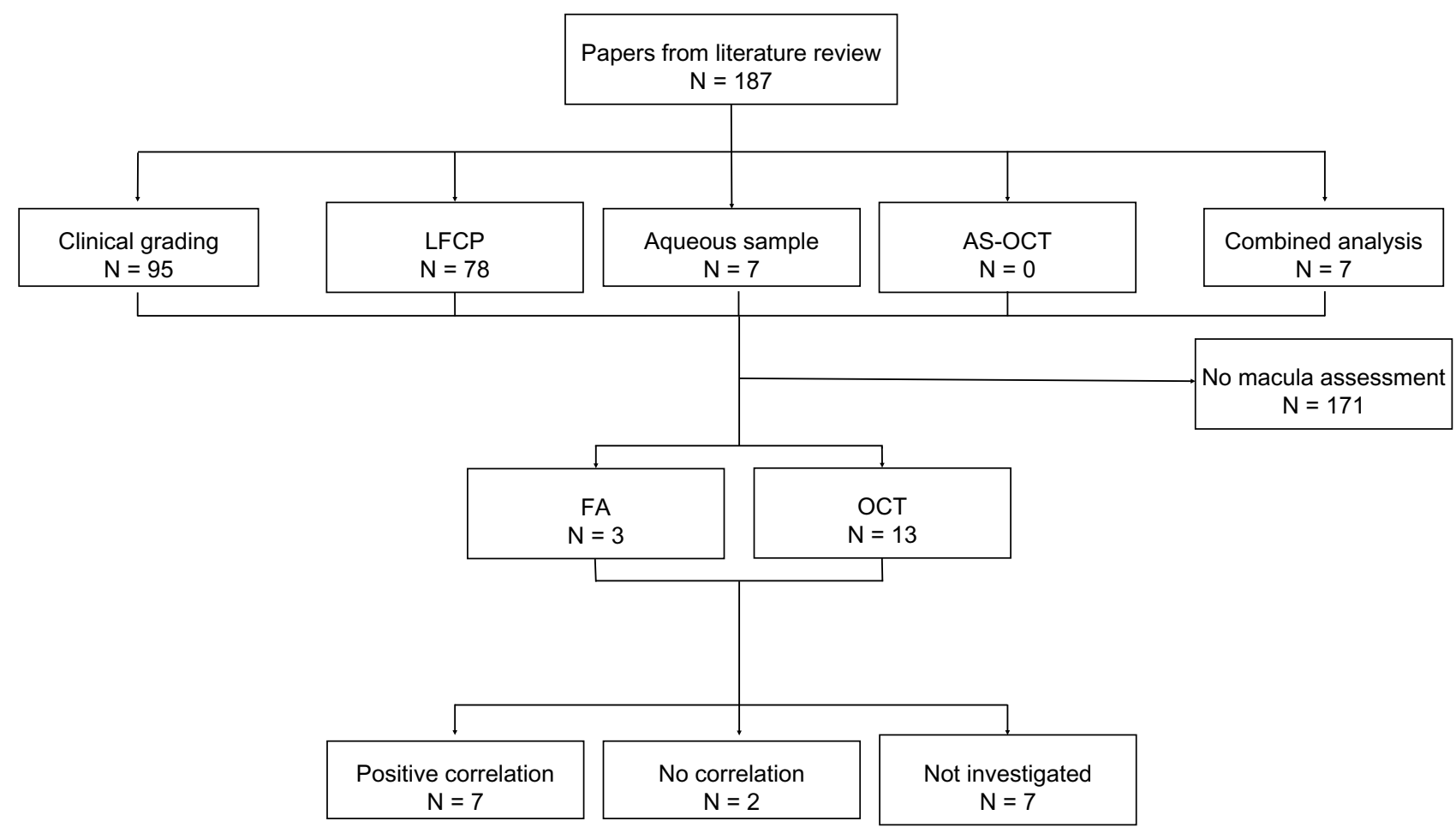

Figure I Literature review process.

Abbreviations: LFCP, Laser Cell and Flare Photometry; AS-OCT, Anterior Segment Optical Coherence Tomography; FA, Fluorescein Angiography; OCT, Optical Coherence Tomography. 


\begin{tabular}{|c|c|c|c|c|c|c|}
\hline 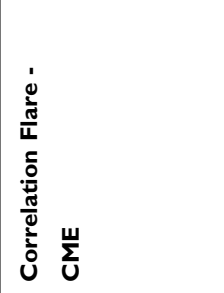 & 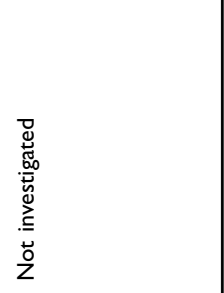 & 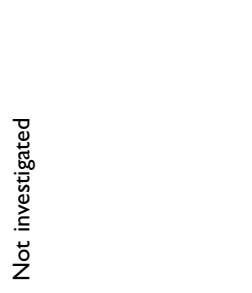 & 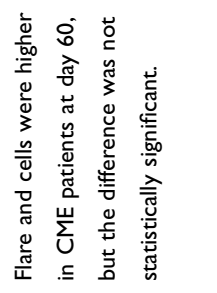 & 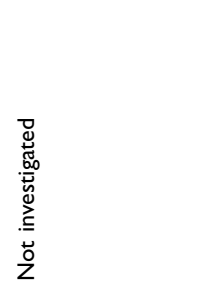 & 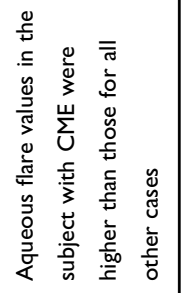 & 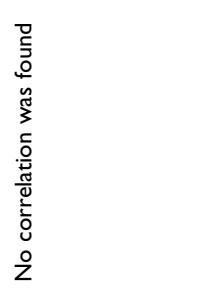 \\
\hline 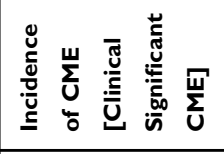 & $\begin{array}{l}\stackrel{\circ}{\circ} \\
\stackrel{\circ}{\circ}\end{array}$ & ํํ & ڤ̊ํํ & 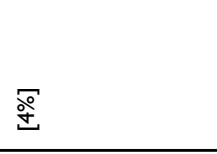 & $\begin{array}{l}\stackrel{\Xi}{\tilde{g}} \\
\stackrel{0}{-} \\
\end{array}$ & $\stackrel{8}{\circ}$ \\
\hline 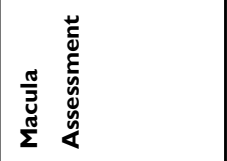 & 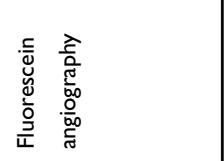 & 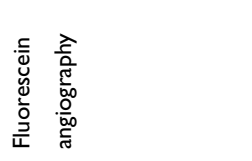 & 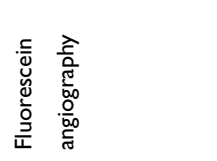 & Ło & ๖ั & $\stackrel{5}{\circ}$ \\
\hline 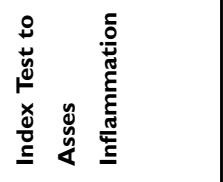 & 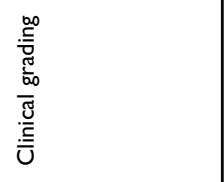 & 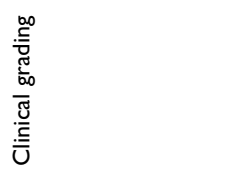 & 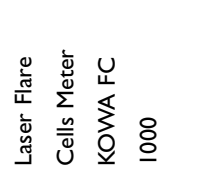 & 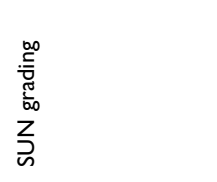 & 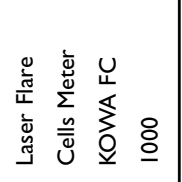 & 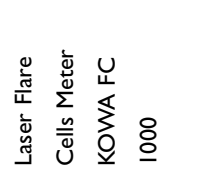 \\
\hline$\frac{0}{3}$ & 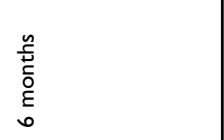 & 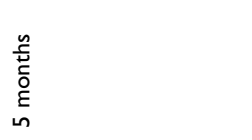 & 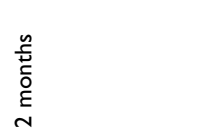 & 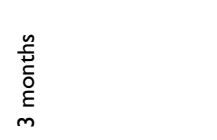 & 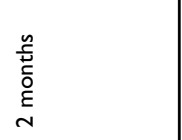 & 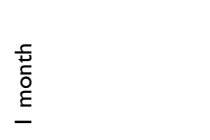 \\
\hline 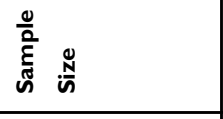 & $\infty$ & $\overline{\mathbf{\infty}}$ & 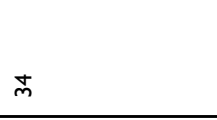 & $\stackrel{\circ}{\circ}$ & $\approx$ & $\underline{\tilde{}}$ \\
\hline 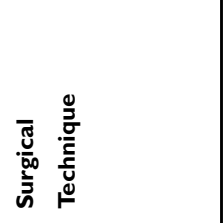 & 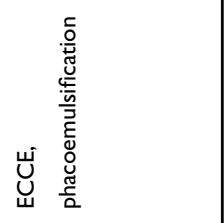 & 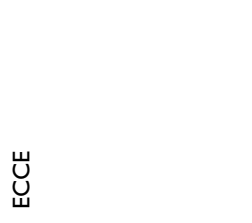 & 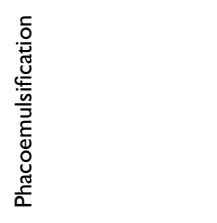 & 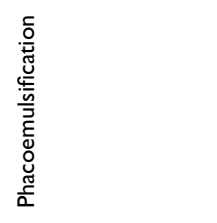 & 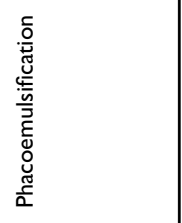 & 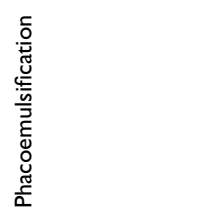 \\
\hline 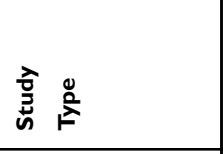 & 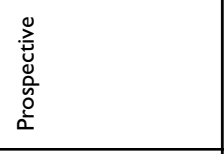 & 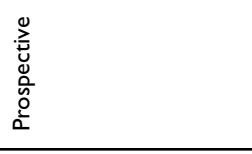 & 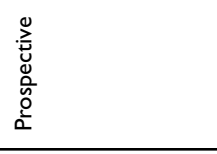 & 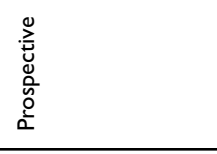 & 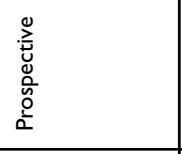 & 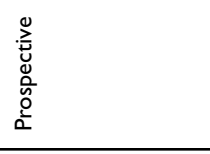 \\
\hline 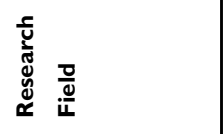 & 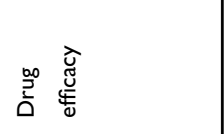 & 离 & 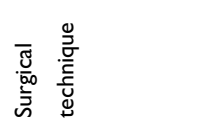 & 足 & 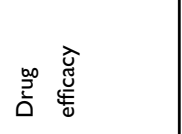 & 紫 \\
\hline$\stackrel{\varrho}{\stackrel{\varrho}{F}}$ & 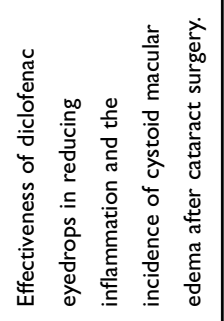 & 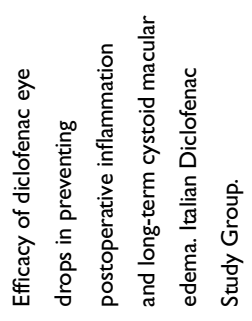 & 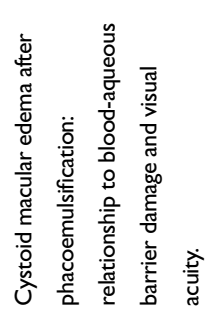 & 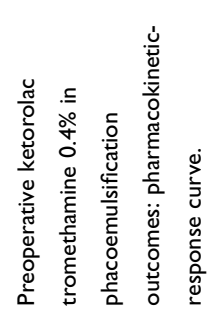 & 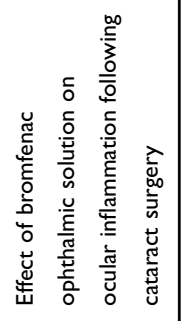 & 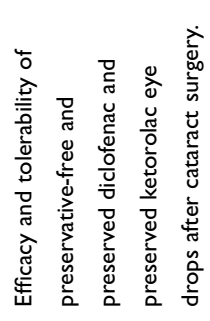 \\
\hline 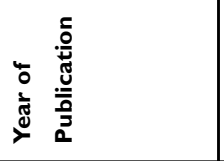 & $\stackrel{\text { ڤ̊ }}{\varrho}$ & $\sigma$ & $\stackrel{\sigma}{\sigma}$ & ঃั & ঃे & $\stackrel{\circ}{\circ}$ \\
\hline 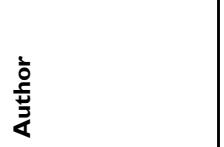 & 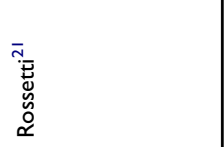 & 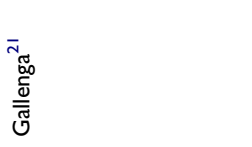 & $\begin{array}{l}\bar{n} \\
\overline{\bar{w}} \\
\bar{\nu}\end{array}$ & 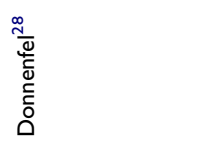 & 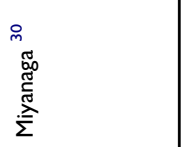 & 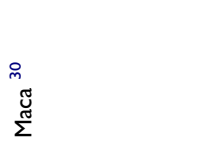 \\
\hline
\end{tabular}




\begin{tabular}{|c|c|c|c|c|c|}
\hline 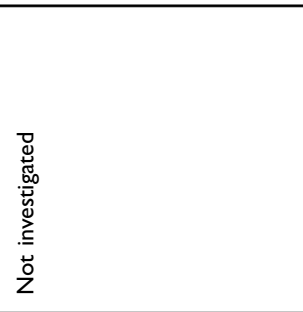 & 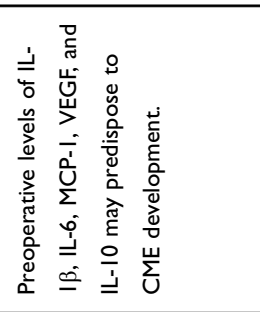 & 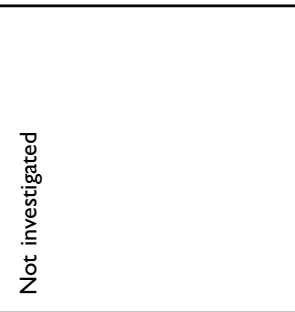 & 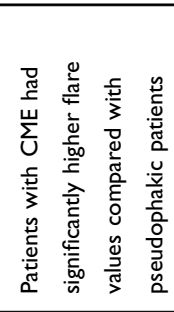 & 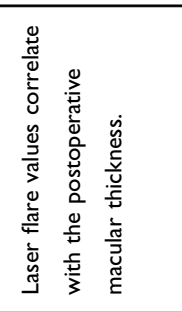 & 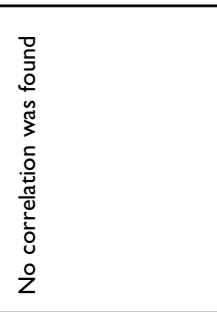 \\
\hline 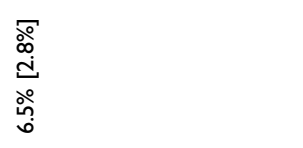 & $\frac{\stackrel{\circ}{\stackrel{\circ}{m}}}{\infty}$ & $\stackrel{+}{\circ}$ & & $\therefore$ & 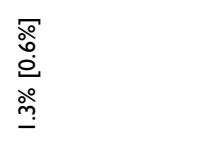 \\
\hline ఫ̊ & $\stackrel{\stackrel{u}{\circ}}{ }$ & $\stackrel{t}{\circ}$ & ť & t. & t. \\
\hline 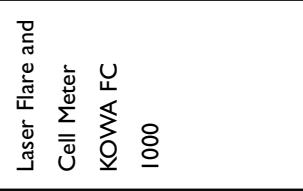 & 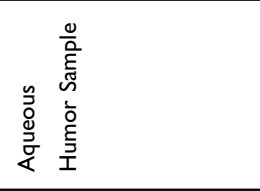 & 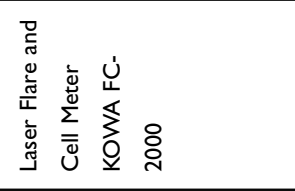 & 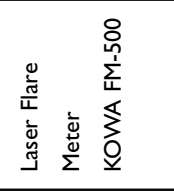 & 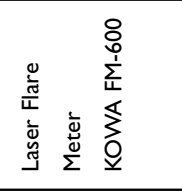 & 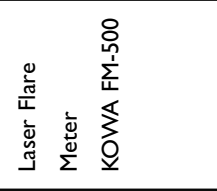 \\
\hline $\begin{array}{l}\text { 言 } \\
\underline{\underline{\underline{\delta}}} \\
\end{array}$ & 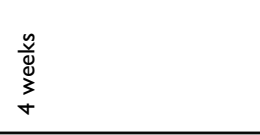 & 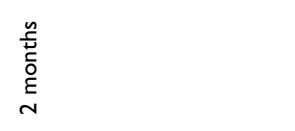 & & 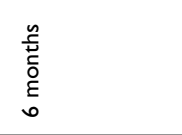 & 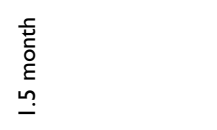 \\
\hline ஓ̊ & $\underset{\sim}{\infty}$ & $\underline{\underline{0}}$ & $\bar{\Omega}$ & $\stackrel{\text { N }}{~}$ & $\underline{\tilde{n}}$ \\
\hline 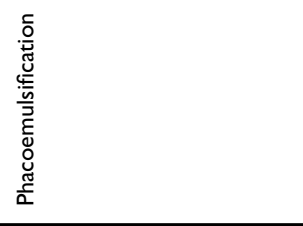 & 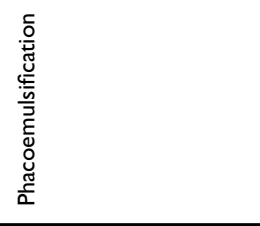 & 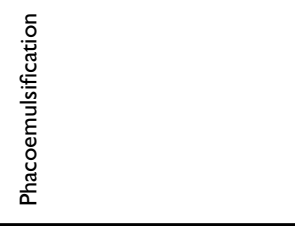 & 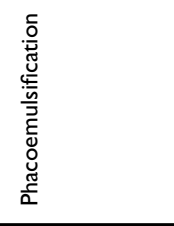 & 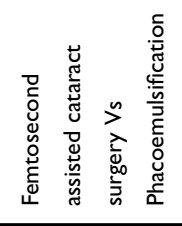 & 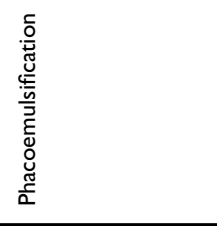 \\
\hline 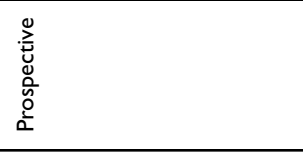 & 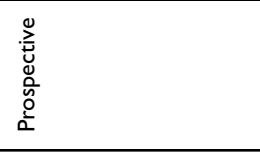 & 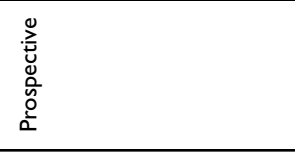 & 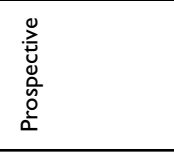 & 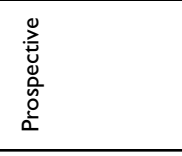 & 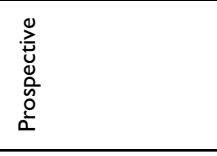 \\
\hline 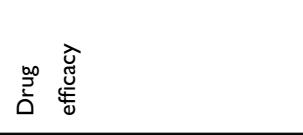 & 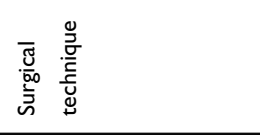 & 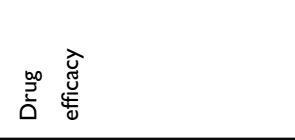 & 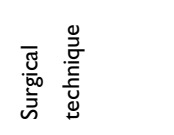 & 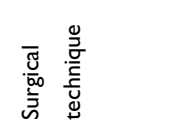 & 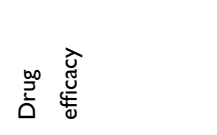 \\
\hline 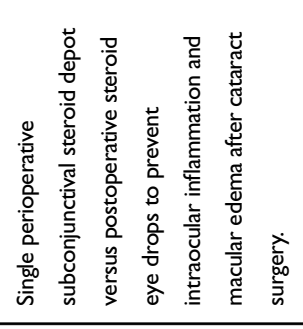 & 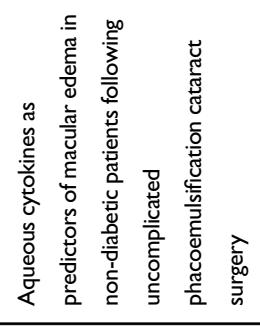 & 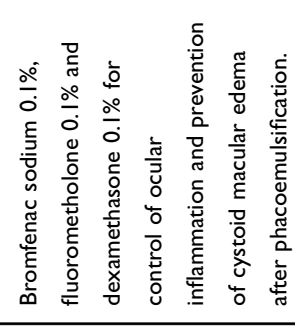 & 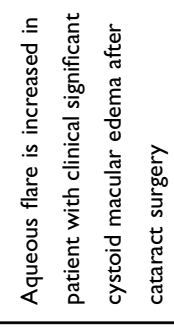 & 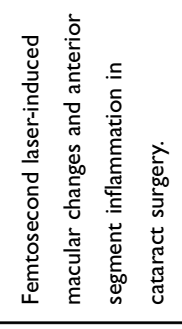 & 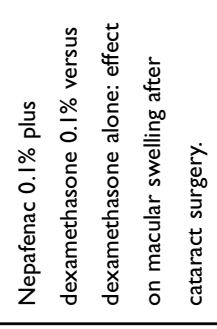 \\
\hline$\overline{\bar{i}}$ & $\stackrel{m}{i}$ & $\stackrel{m}{i}$ & $\stackrel{m}{\bar{a}}$ & $\stackrel{t}{\stackrel{5}{*}}$ & $\stackrel{t}{9}$ \\
\hline 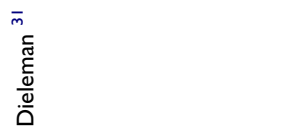 & 䇰 & 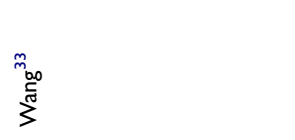 & $\begin{array}{l}\text { 品 } \\
\text { 咅 }\end{array}$ & 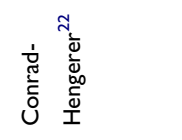 & 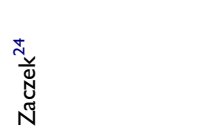 \\
\hline
\end{tabular}




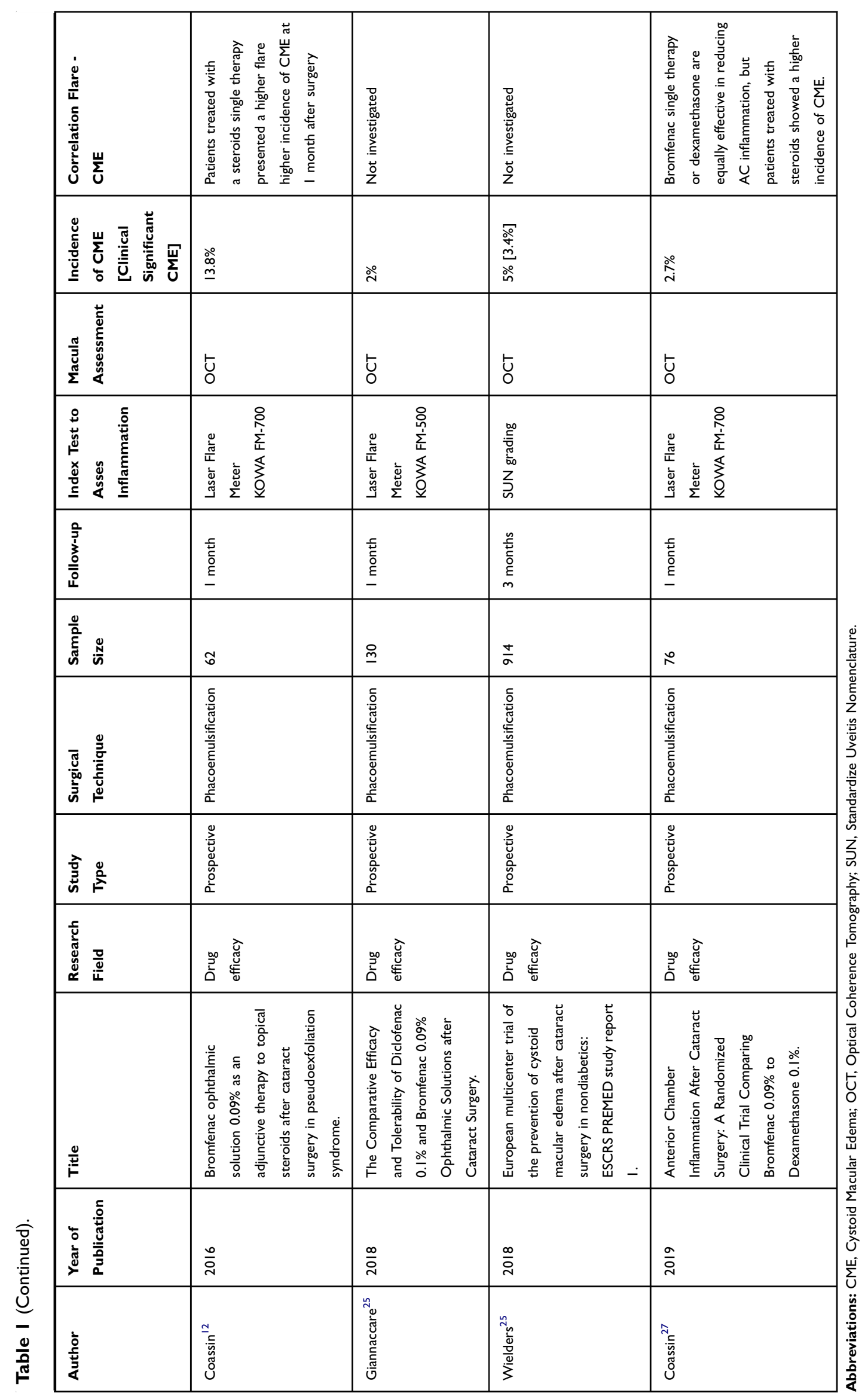


degree in uveitis is usually higher than after uncomplicated cataract extraction, and therefore the detection of minimum variations during follow-up may appear more complicated when a clinical grading system is adopted. Due to its qualitative nature, SUN grading has a moderate reproducibility for agreement between different observers; therefore, more objective techniques of $\mathrm{AC}$ inflammation assessment are desired, especially when different clinicians are involved. ${ }^{35}$ Furthermore, different types of equipment are proved factors of variability. Various slit lamps and lighting sources influence the ability to recognize cells and flare. ${ }^{36}$ Therefore, using SUN grading, standardization of the equipment, and observers training are crucial to collect consistent and comparable data on the inflammatory level when different centres are involved. An additional limitation of SUN grading could be its low sensitivity. The close range of cells per high-power field between grade 1+ $(6-15$ cells/high power field) and grade $2+(16-25$ cells/high power field) may affect the ability in detecting minimum variations, within the lowest grades of inflammation. ${ }^{37}$ This issue is relevant in the follow-up of patients after phacoemulsification, where lower amount of inflammation is expected compared to uveitis, and subtle improvements occurring over time may pass unrecognized using a clinical grading score. ${ }^{38}$

According to the SUN criteria, "improved activity" is, by definition, a 2-step improvement or recovering to grade $0 .{ }^{17}$ As stated by these criteria, it is evident the lack of linear progression between different clinical scores. An improvement from $2+$ cells $(16-25$ cells/high power field) to $0.5+$ ( $1-5$ cells/high power field) is rated the same as $3+(26-50$ cells/high power field) to $1+$ cells $(5-10$ cells/high power field), even if the effective range of cells is different passing from grade $2+$ to $0.5+$ (decrease of $15-20$ cells/high power field) and from grade 3+ to 1+ (decrease of 21-40 cells/high power field). In clinical trials, the lack of a linear progression may consistently affect the recording of clinical data and their analysis, neglecting possible improvements in some cases or worsening in others. A treatment could be wrongly declared ineffective despite a consistent improvement in inflammation not accurately detected. Defining the efficacy of a novel therapy may benefit from a linear grading scale.

\section{Laser Flare and Cell Photometer (LFCP)}

LFCP, firstly described in $1988^{18}$ and commercialized in 1989, adopts a laser beam to measures the back-scattered light from proteins and cells into the $\mathrm{AC}$ by a photomultiplier. In principle, the amount of backscattered light is proportional to the concentration of proteins, particles, or cells in the AC; therefore, the higher is the concentration, the higher is the output signal. The amount of inflammation is measured in photon count per milliseconds $(\mathrm{ph} / \mathrm{ms}){ }^{18,39}$

Through the years, various models of LFCP have been commercialized. Differently from laser flare meters (KOWA FM-500, FM-600, FM-700), flare and cell meters (KOWA FC-1000, FC-2000) can also measure the number of cells adopting two optical scanners to analyze twodimensionally a $0.5 \mathrm{~mm}^{3}$ volume into the anterior chamber. The number of picks in the output signal corresponds to the number of cells into the scanned fixed volume. ${ }^{39}$

A faint flair (2.9-3.9 ph/ms between 20-40 years of age, increasing to $5.0-6.5 \mathrm{ph} / \mathrm{ms}$ between $70-80$ years of age $)^{40-42}$ is present in physiological condition, but not detectable using a slit lamp. After cataract surgery, laser flare can reach values of a maximum of $30-40 \mathrm{ph} / \mathrm{ms}$, considerably lower than those measured in uveitis. ${ }^{43}$ Validation of measures obtained from LFCP results from laboratory studies demonstrated that $\mathrm{ph} / \mathrm{ms}$ values correlate with the real protein concentration in the aqueous samples collected from patients with uveitis undergoing intraocular surgery. ${ }^{40,41,44-47}$ Furthermore, Saari et al published a formula to calculate the real concentration of proteins using the photon counts of the LFCP. ${ }^{45}$

A correlation between laser flare values and the SUN grading system has been proved, specifically in the setting of uveitis, while no studies so far analyzed this correspondence after cataract surgery, probably because of the low inflammation amount after uneventful phacoemulsification. LFCP can detect a minimum variation of cells and flare within the same grade of the SUN system both at the lower or, the higher grades, confirming a high level of sensitivity, reproducibility, and repeatability of LFCP measurements. ${ }^{39}$

In the setting of cataract surgery, LFCP has been used to quantitatively investigate postsurgical inflammation allowing clinicians to compare between different surgical techniques, ${ }^{48-50}$ several postoperative anti-inflammatory treatments $^{12,26,51-53}$ and various eye conditions that may complicate with a higher level of inflammatory response after surgery. ${ }^{12}$

In the scenario of uncomplicated cataract surgery, we believe that an instrument able to detect the minimum amount of inflammation is mandatory to conduct rigorous research with no bias induced by interobserver variations or differences in the equipment employed among centres. 
Each SUN clinical-grade presents a wide range of laser flare values, with an overlap of flare readings passing from the lowest to highest score. ${ }^{39}$

Tugalt-Tutkun et al reported an increased coefficient of variation passing from grade $3+$ to 0 (coefficient of variation is $81.4 \%$ for grade $0,69.9 \%$ for grade $1,42.2 \%$ for grade $2+$, and $25.8 \%$ for grade $3+$ ). ${ }^{39}$ These results confirm that the human eye is not capable of distinguishing minimal, though clinically relevant inflammatory variations, especially at the lower grades as after cataract surgery. The overlap in the lower clinical grading reflects the difficulties in recognizing the real amount of inflammation when a subjective method of measurement is adopted. These values would correspond to 0 or 1 of the SUN grading, and it would be challenging to recognize minimum inflammatory variations using the slit lamp.

Several studies investigated the effect of different topical therapies on limiting the risk of CME after cataract surgery, but only a handful of them have analyzed the correlation between LFCP readings and the frequency of any macular changes or CME.

Ersoy et al analyzed laser flare values in patients with clinically significant CME after uncomplicated cataract surgery. ${ }^{34}$ Patients with CME had significantly higher flare values than pseudophakic patients without CME during and after the first month following phacoemulsification. As a marker for inflammation and breakdown of the blood-retinal barrier, LFCP values suggest that controlling postoperative inflammation might be the key to avoid or treat CME. Ursell et al used fluorescein angiography to detect CME after uncomplicated phacoemulsification. ${ }^{27}$ They demonstrated that the laser flare readings were higher in patients with angiographic CME, but the difference was not statistically significant. Maca et al failed to prove any correlation between mean foveal thickness and AC laser flare photometry. ${ }^{30}$ Conrad-Hengerer et al, investigating the inflammatory response after the femtosecondassisted cataract surgery, demonstrated that laser flare values correlate with the postoperative OCT macular thickness and higher the $\mathrm{ph} / \mathrm{ms}$ higher was the macular thickness. ${ }^{22}$ Zaczek et al found no correlation between laser flare value and total OCT macular volume after uncomplicated phacoemulsification. ${ }^{23}$ Finally, Miyanaga et al investigated the effect of Bromfenac ophthalmic solution on ocular inflammation following cataract surgery using the LFCP. ${ }^{29}$ They reported a single case of CME in which the aqueous flare values were higher compared to the ones of patients without CME. Recently,
Coassin et al reported on the effect of combined therapy using bromfenac and dexamethasone in patients with PEX who underwent cataract surgery. They observed that patients treated with combined therapy of steroid and NSAID presented lower flare values and incidence of CME one month after surgery compared to patients treated with steroids alone. ${ }^{12}$

According to this review, 6 out of 11 studies employing LFCP documented some relationship between the degree of AC inflammation and the risk of CME after uncomplicated phacoemulsification.

Undoubtedly, LFCP presents some limitations. The instrument requires a longer processing time compared to the SUN clinical grading because several measurements (from 5 to 7$)^{39}$ are required to obtain an average value. Moreover, the examination needs to be conducted in a completely dark room and necessitates sufficient patient cooperation to obtain a reliable analysis. Corneal edema on the first operative day may impair the analysis, because of "background errors" that interfere with LFCP correct readings. Furthermore, this technology involves the costs of buying and maintenance.

\section{Optical Coherence Tomography}

The advent of OCT has optimized the diagnosis of pseudophakic CME by detecting very initial signs of macular swelling and cysts even before the reduction of visual acuity. Nowadays, last generation OCTs allows clinicians to analyze in detail all the retinal layers, the choroid, the vitreous cavity, and the AC. In the field of inflammation, the use of OCT for direct visualization of vitreous inflammatory cells in patients with uveitis has been recently described. ${ }^{54}$ Keane et al obtained measurements of vitreous signal intensity from OCT in patients with uveitis with the aim of objectively and quantitatively evaluating the intraocular inflammatory activity. They demonstrated that Vitreous/Retinal Pigment Epithelium-relative intensity (VIT/RPE relative intensity) was significantly higher in eyes with active posterior uveitis compared to the vitreous signal of inactive uveitis or healthy controls. Moreover, the VIT/RPE-relative intensity showed a significant positive correlation with the clinical vitreous haze. These results provided evidence that OCT-derived measurements can provide a quantitative assessment of intraocular inflammation. ${ }^{55}$

In line with these findings, thanks to the technological refinements of anterior segment-OCT (AS-OCT), authors described the feasibility of AS-OCT to recognize 
inflammatory cells and flare and to obtain an objective quantification of the inflammation in the AC. ${ }^{38}$

Concerning cells, the majority of papers adopted a time-domain OCT with a spatial resolution larger than the white cells, arising uncertainty on the interpretation of the real nature of the "white spots" inside the AC. ${ }^{56-58}$

Spectral-domain OCT (SD-OCT) has a higher resolution than the previous models. Sharma et al described the proficiency of SD-OCT in detecting inflammatory cells in the AC thanks to an automated algorithm that counts cells in a $3 \mathrm{D}$ volume scan. After comparing these data to the SUN grading, they demonstrated a high positive correlation between clinical grading and the number of cells identified by SD-OCT. ${ }^{38}$ Recently, Inverinizzi et al ${ }^{59}$ proposed a new method to measure both cells and flare using a swept-source AS-OCT. They adopted an optical density ratio calculated as the comparison between the signal inside the AC and the signal outside the eye (aqueous-toair relative intensity $[\mathrm{ARI}]$ index). Active uveitis patients present a significantly higher ARI index compared with inactive uveitis and controls. Nonetheless, a positive correlation between the ARI index and the SUN clinical grading has been shown.

To date, no clinical trials have employed AS-OCT to measure AC inflammation after cataract surgery. The use of AS-OCT to analyze AC inflammation is still in its infancy, but it appears to be promising being a highly reproducible method for measuring flare and cells in the AC.

\section{Aqueous Humor Sample Analysis}

The pathogenesis of pseudophakic CME appears to be associated with postoperative inflammation primarily induced by prostaglandins and other proinflammatory mediators. ${ }^{9,60}$ Inflammatory mediators alter the bloodretinal and the blood-aqueous barriers, leading to increased vascular permeability. ${ }^{61}$ The majority of studies, so far, focused on a limited number of molecules present in humour aqueous. ${ }^{62}$ Exploring a higher number of cytokines would provide broader insight into the inflammatory mechanisms involved.

The aqueous humour analysis is directed to the quantification and classification of the different cytokines and chemokines using the enzyme-linked immunosorbent assay (ELISA). A potential limitation of this technique is that it requires at least $50-100 \mu \mathrm{L}$ of aqueous humour for every single molecule of interest. Considered that the aqueous sample amount collected is about $0.15-0.20 \mathrm{~mL}$, it is challenging to test the complete pattern of inflammatory mediators, which amounts to over 650 different identified proteins. $^{63}$ This limitation is especially important in the setting of cataract surgery in which the eye is generally not inflamed at the time of surgery. The aqueous sample needs to be performed at the beginning of the procedure before any other fluid is introduced in the AC. In these circumstances, the amount of inflammatory mediators in the early phase of the procedure is too low to understand the multiple networks of cytokines and chemokines that may be involved. These technical problems have led to confusion in this field with no consistent results on the relevance of individual mediators in this specific condition. ${ }^{19}$

Nowadays, many alternative technologies allow a more comprehensive analysis of pro- and anti-inflammatory mediators using a smaller amount of aqueous humour. The most recent innovation in the analysis of the aqueous sample comes from the refining of proteomics technique. ${ }^{63}$ Multiplexed beads immunoassay can perform simultaneous analysis of different mediators thanks to their individual fluorescent properties. The main advantage of this technique is the ability to measure numbers of molecules in a single aqueous sample of $25-100 \mu \mathrm{L} .^{20,64,65}$ These modern techniques allow clinicians to characterize the complex network of cytokines and chemokines both at rest or in inflammatory conditions. ${ }^{19} \mathrm{Chu}$ et $\mathrm{al}^{32}$ using multiplex assays, simultaneously measured the concentrations of 27 cytokines in aqueous humour samples as predictors of CME in non-diabetic patients following uncomplicated phacoemulsification surgery. The concentrations of IL-1 $\beta$, IL-6, MCP-1, and VEGF were significantly higher in patients with CME. Also, the aqueous humour levels of IL-1 $\beta$, IL6 , MCP-1, and VEGF correlated positively with postoperative central foveal thickness.

The introduction of femtosecond laser-assisted cataract surgery made it possible to evaluate the release of inflammatory mediators into the $\mathrm{AC}$ immediately after the application of the laser and before phacoemulsification. In a comparative study, Liu et $\mathrm{al}^{66}$ reported that femtosecond laser treatment induced significantly higher humour aqueous levels of pro-inflammatory cytokines and PGE2 compared to standard phacoemulsification. Furthermore, the postoperative flare was higher, although not significantly, in the femtosecond-assisted group than in the standard phacoemulsification group; however, in this study, no analysis of the macula thickness was conducted.Harvesting aqueous humour remains a controversial procedure in prospective clinical trials on cataract surgery, as it would be 
unethical to obtain consecutive samples in the same patients during follow-up due to the invasiveness of the procedure.

Currently, it is difficult to understand the real pattern of molecules involved in the inflammatory process after cataract surgery because sampling may be performed only at the beginning of the procedure, with a limited amount of inflammatory mediators that can be collected and investigated.

\section{Conclusion}

Proving a possible correlation between AC inflammation and the risk of postoperative CME is challenging as it inevitably requires quantitative methods of measurement. Clinical grading, according to the SUN method, has proved to be useful to score inflammation at slit lamp in routine clinical practice. However, the low sensitivity, reproducibility, repeatability, and the absence of a linear scale both for cells and flare are significant limitations, especially when numerical data are required to state the efficacy of novel treatments and to make a comparison with other clinical trials. No study has so far attempted or found a correlation between the clinical grade of postoperative $\mathrm{AC}$ inflammation and the risk of CME development.

The AS-OCT analysis is a non-invasive, objective, and quantitative method to measure intraocular inflammation. Though, it appears potentially useful in the setting of clinical trials on cataract surgery in order to provide comparable numerical data of AC inflammation. This technology needs to be improved by developing dedicated software of analysis that may allow introducing this technique to the routine clinical practice.

The most recent techniques of proteomics with the immunoassay have dramatically increased the overall knowledge of the complex network of cytokines and chemokines involved in AC inflammation. Future research should aim to extend the panel of the molecules investigated and to provide better diagnostic and prognostic information, identifying new therapeutic targets. The main limitation is that it is unethical to perform multiple aqueous sampling after surgery in order to prospectively address the real pattern of inflammatory mediators after phacoemulsification and their specific role in the pathogenesis of pseudophakic CME.

Probably, the LFCP may represent the right compromise in the setting of clinical trials based on cataract surgery. It allows precise measurements of both cells and flares inside the $\mathrm{AC}$, and it correlates positively with clinical grading. However, flare and cell meters do not distinguish inflammatory cells from pigment and debris (lens particles) that may be mistakenly counted as cells. Since the inflammation after uncomplicated cataract surgery is extremely low, a laser flare meter is adequate to obtain a reliable measure of the blood-aqueous barrier breakdown. LFCP is characterized by a low learning curve, differently from the expertise required to provide a correct SUN score. Additionally, it is not excessively time-consuming, compared to AS-OCT, and may not affect too much the flow of routine clinical activity.

Despite no studies in the literature were specifically designed to correlate AC inflammation, measured by LFCP, and macular changes occurring after cataract surgery, some studies have documented a link between the degree of inflammation occurring after surgery and the frequency of CME. ${ }^{12,22,26,27,29,34}$

To measure inflammation and provide comparable numbers is the focal point in the setting of a clinical trial investigating treatment and prevention of inflammation and cystoid macular edema after cataract surgery. In order to acquire reproducible and comparable data, it is mandatory to adopt methods of measurements that precisely and quantitatively assess AC inflammation, aiming to correlate the inflammatory process to risk of development of cystoid macular edema after uncomplicated cataract surgery.

\section{Disclosure}

No author has a financial or proprietary interest in any material or method mentioned in this study. The authors received no funding for the publication of this article.

\section{References}

1. Wang W, Yan W, Fotis K, et al. Cataract surgical rate and socioeconomics: a global study. Invest Ophthalmol Vis Sci. 2016. doi:10.1167/ iovs.16-19894

2. Davis G. The evolution of cataract surgery. Mo Med. 2016.

3. Kim SJ, Schoenberger SD, Thorne JE, et al. Topical nonsteroidal anti-inflammatory drugs and cataract surgery: a report by the American Academy of Ophthalmology. Ophthalmology. 2015;122:2159-2168. doi:10.1016/j.ophtha.2015.05.014

4. McCafferty S, Harris A, Kew C, et al. Pseudophakic cystoid macular edema prevention and risk factors; prospective study with adjunctive once daily topical nepafenac $0.3 \%$ versus placebo. BMC Ophthalmol. 2017;17. doi:10.1186/s12886-017-0405-7

5. Pollack A, Leiba H, Bukelman A, Oliver M. Cystoid macular oedema following cataract extraction in patients with diabetes. $\mathrm{Br}$ J Ophthalmol. 1992;76:221-224. doi:10.1136/bjo.76.4.221

6. Schmier JK, Halpern MT, Covert DW, Matthews GP. Evaluation of costs for cystoid macular edema among patients after cataract surgery. Retina. 2007;27:621-628. doi:10.1097/01.iae.0000249577.92800.c0

7. Chu CJ, Johnston RL, Buscombe C, Sallam AB, Mohamed Q, Yang YC. Risk factors and incidence of macular edema after cataract surgery a database study of 81984 eyes. Ophthalmology. 2016;123:316-323. doi:10.1016/j.ophtha.2015.10.001 
8. Flach AJ. The incidence, pathogenesis and treatment of cystoid macular edema following cataract surgery. Trans Am Ophthalmol Soc. 1998. doi:10.1136/bjo.2004.047662

9. Gulkilik G, Kocabora S, Taskapili M, Engin G. Cystoid macular edema after phacoemulsification: risk factors and effect on visual acuity. Can J Ophthalmol. 2007. doi:10.1139/106-062

10. Bélair M-L, Kim SJ, Thorne JE, et al. Incidence of cystoid macular edema after cataract surgery in patients with and without uveitis using optical coherence tomography. Am J Ophthalmol. 2009;148 (1):128-35.e2. doi:10.1016/j.ajo.2009.02.029

11. Henderson BA, Kim JY, Ament CS, Ferrufino-Ponce ZK, Grabowska A, Cremers SL. Clinical pseudophakic cystoid macular edema. Risk factors for development and duration after treatment. J Cataract Refract Surg. 2007;33:1550-1558. doi:10.1016/j.jcrs.2007.05.013

12. Coassin M, Iovieno A, Soldani A, et al. Bromfenac ophthalmic solution $0.09 \%$ as an adjunctive therapy to topical steroids after cataract surgery in pseudoexfoliation syndrome. J Cataract Refract Surg. 2018:1119-1125. doi:10.1016/j.jcrs.2016.04.031

13. Perente I, Utine CA, Ozturker C, et al. Evaluation of macular changes after uncomplicated phacoemulsification surgery by optical coherence tomography. Curr Eye Res. 2007;32:241-247. doi:10.1080/ 02713680601160610

14. Vukicevic M, Gin T, Al-Qureshi S. Prevalence of optical coherence tomography-diagnosed postoperative cystoid macular oedema in patients following uncomplicated phaco-emulsification cataract surgery. Clin Exp Ophthalmol. 2012;40:282-287. doi:10.1111/j.1442-9071.2011.02638.x

15. Rossetti L, Autelitano A. Cystoid macular edema following cataract surgery. Curr Opin Ophthalmol. 2000;11:65-72. doi:10.1097/00055 735-200002000-00010

16. Miyake K, Ibaraki N. Prostaglandins and cystoid macular edema. Surv Ophthalmol. 2002;47:S203-S218. doi:10.1016/S0039-6257(02) 00294-1

17. Jabs DA, Nussenblatt RB, Rosenbaum JT, et al. Standardization of uveitis nomenclature for reporting clinical data. Results of the first international workshop. Am J Ophthalmol. 2005. doi:10.1016/j. ajo.2005.03.057

18. Sawa M, Tsurimaki Y, Tsuru T, Shimizu H. New quantitative method to determine protein concentration and cell number in aqueous in vivo. Jpn J Ophthalmol. 1988;32(2):132-142.

19. Jones VS, Wu J, Zhu SW, Huang RP. Application of multiplex immunoassay technology to investigations of ocular disease. Expert Rev Mol Med. 2016;18. doi:10.1017/erm.2016.15

20. Rossetti L, Bujtar E, Castoldi D, Torrazza C, Orzalesi N. Effectiveness of diclofenac eyedrops in reducing inflammation and the incidence of cystoid macular edema after cataract surgery. J Cataract Refract Surg. 1996;22:794-799. doi:10.1016/S0886-3350(96)80164-7

21. Gallenga PE, Mastropasqua L, Lobefalo L, et al. Efficacy of diclofenac eyedrops in preventing postoperative inflammation and long-term cystoid macular edema. J Cataract Refract Surg. 1997;23:1183-1189. doi:10.1016/S0886-3350(97)80313-6

22. Conrad-Hengerer I, Hengerer FH, Al Juburi M, Schultz T, Dick HB. Femtosecond laser-induced macular changes and anterior segment inflammation in cataract surgery. $J$ Refract Surg. 2014;30:222-226. doi:10.3928/1081597x-20140321-01

23. Zaczek A, Artzen D, Laurell CG, Stenevi U, Montan P. Nepafenac $0.1 \%$ plus dexamethasone $0.1 \%$ versus dexamethasone alone: effect on macular swelling after cataract surgery. J Cataract Refract Surg. 2014;40:1498-1505. doi:10.1016/j.jcrs.2013.12.023

24. Giannaccare G, Finzi A, Sebastiani S, Greco F, Versura P, Campos EC. The comparative efficacy and tolerability of diclofenac $0.1 \%$ and Bromfenac $0.09 \%$ ophthalmic solutions after cataract surgery. Curr Eye Res. 2018;43:1445-1453. doi:10.1080/02713683.2018.1501489

25. Wielders LHP, Schouten JSAG, Winkens B, et al. European multicenter trial of the prevention of cystoid macular edema after cataract surgery in nondiabetics: ESCRS PREMED study report 1. J Cataract Refract Surg. 2018;44(4):429-439. doi:10.1016/j.jcrs.2018.01.029
26. Coassin M, De Maria M, Mastrofilippo V, et al. Anterior chamber inflammation after cataract surgery: a randomized clinical trial comparing Bromfenac $0.09 \%$ to Dexamethasone $0.1 \%$. Adv Ther. 2019;36:2712-2722. doi:10.1007/s12325-019-01076-4

27. Ursell PG, Spalton DJ, Whitcup SM, Nussenblatt RB. Cystoid macular edema after phacoemulsification: relationship to blood- aqueous barrier damage and visual acuity. $J$ Cataract Refract Surg. 1999;25:1492-1497. doi:10.1016/S0886-3350(99)00196-0

28. Donnenfeld ED, Perry HD, Wittpenn JR, Solomon R, Nattis A, Chou T. Preoperative ketorolac tromethamine $0.4 \%$ in phacoemulsification outcomes: pharmacokinetic-response curve. J Cataract Refract Surg. 2006;32:1474-1482. doi:10.1016/j.jcrs.2006.04.009

29. Miyanaga M, Miyai T, Nejima R, Maruyama Y, Miyata K, Kato S. Effect of bromfenac ophthalmic solution on ocular inflammation following cataract surgery. Acta Ophthalmol. 2009;87:300-305. doi:10.1111/j.1755-3768.2008.01433.x

30. Maca SM, Amon M, Findl O, Kahraman G, Barisani-Asenbauer T. Efficacy and tolerability of preservative-free and preserved diclofenac and preserved ketorolac eyedrops after cataract surgery. Am J Ophthalmol. 2010;149:777-784. doi:10.1016/j.ajo.2009.12.010

31. Dieleman M, Wubbels RJ, Van Kooten-noordzij M, De Waard PWT. Single perioperative subconjunctival steroid depot versus postoperative steroid eyedrops to prevent intraocular inflammation and macular edema after cataract surgery. J Cataract Refract Surg. 2011;37:1589-1597. doi:10.1016/j.jcrs.2011.03.049

32. Chu L, Wang B, Xu B, Dong N. Aqueous cytokines as predictors of macular edema in non-diabetic patients following uncomplicated phacoemulsification cataract surgery. Mol Vis. 2013;19:2418-2425.

33. Wang QW, Yao K, Xu W, et al. Bromfenac sodium 0.1\%, fluorometholone $0.1 \%$ and dexamethasone $0.1 \%$ for control of ocular inflammation and prevention of cystoid macular edema after phacoemulsification. Ophthalmologica. 2013;229:187-194. doi:10.1159/000346847

34. Ersoy L, Caramoy A, Ristau T, Kirchhof B, Fauser S. Aqueous flare is increased in patients with clinically significant cystoid macular oedema after cataract surgery. Br J Ophthalmol. 2013;97:862-865. doi:10.1136/bjophthalmol-2012-302995

35. Kempen JH, Ganesh SK, Sangwan VS, Rathinam SR. Interobserver agreement in grading activity and site of inflammation in eyes of patients with Uveitis. Am J Ophthalmol. 2008;146:813-818.e1. doi:10.1016/j.ajo.2008.06.004

36. Wong IG, Nugent AK, Vargas-Martín F. The effect of biomicroscope illumination system on grading anterior chamber inflammation. Am J Ophthalmol. 2009;148:516-520.e2. doi:10.1016/j.ajo.2009.04.027

37. Sen HN, Read RW. In: Sen HN, Read RW, editors. Multimodal Imaging in Uveitis. Cham: Springer International Publishing; 2018. doi:10.1007/978-3-319-23690-2

38. Sharma S, Lowder CY, Vasanji A, Baynes K, Kaiser PK, Srivastava SK. Automated analysis of anterior chamber inflammation by spectral-domain optical coherence tomography. Ophthalmology. 2015;122:1464-1470. doi:10.1016/j.ophtha.2015.02.032

39. Tugal-Tutkun I, Herbort CP. Laser flare photometry: a noninvasive, objective, and quantitative method to measure intraocular inflammation. Int Ophthalmol. 2010;30:453-464. doi:10.1007/s10 792-009-9310-2

40. Shah SM, Spalton DJ, Smith SE. Measurement of aqueous cells and flare in normal Eyes. $\mathrm{Br} J$ Ophthalmol. 1991. doi:10.1136/bjo. 75.6 .348

41. Onodera T, Gimbel HV, DeBroff BM. Aqueous flare and cell number in healthy eyes of Caucasians. Jpn J Ophthalmol. 1993;37(4):445-451.

42. Guillén-Monterrubio OM, Hartikainen J, Taskinen K, Saari KM. Quantitative determination of aqueous flare and cells in healthy eyes. Acta Ophthalmol Scand. 2009;75(1):58-62. doi:10.1111/j.16000420.1997.tb00251.x

43. Ladas JG, Wheeler NC, Morhun PJ, Rimmer SO, Holland GN. Laser flare-cell photometry: methodology and clinical applications. Surv Ophthalmol. 2005;50(1):27-47. doi:10.1016/j.survophthal.2004.10.004 
44. Rodinger ML, Hessemer V, Schmitt K, Schickel B [Reproducibility of in vivo determination of protein and particle concentration with the laser flare cell photometer]. Reproduzierbarkeit der in-vivoBestimmung von Eiweiss- und Partikelkonzentration mit dem Laserflare-cell-Photometer. 1993.

45. Saari KM, Guillen-Monterrubio OM, Hartikainen J, Hamalainen MM, Taskinen K. Measurement of protein concentration of aqueous humour in vivo: correlation between laser flare measurements and chemical protein determination. Acta Ophthalmol Scand. 1997.

46. Guillén-Monterrubío OM, Hartikainen J, Taskinen K, Saari KM. Quantitative determination of aqueous flare and cells in healthy eyes. Acta Ophthalmol Scand. 1997;75(1):58-62. doi:10.1111/ j.1600-0420.1997.tb00251.x

47. El-Harazi SM, Ruiz RS, Feldman RM, Chuang AZ, Villanueva G. Quantitative assessment of aqueous flare: the effect of age and pupillary dilation. Ophthalmic Surg Lasers. 2002. 33(5):379-82.

48. Laurell CG, Zetterström C, Philipson B, Syrén-Nordqvist S. Randomized study of the blood-aqueous barrier reaction after phacoemulsification and extracapsular cataract extraction. Acta Ophthalmol Scand. 1998;76:573-578. doi:10.1034/j.1600-0420.1998.760512.x

49. Dick HB, Schwenn O, Krummenauer F, Krist R, Pfeiffer N. Inflammation after sclerocorneal versus clear corneal tunnel phacoemulsification. Ophthalmology. 2000;107:241-247. doi:10.1016/S0161-6420(99)00 082-2

50. Schwenn O, Dick HB, Krummenauer F, Christmann S, Vogel A, Pfeiffer N. Healon5 versus Viscoat during cataract surgery: intraocular pressure, laser flare and corneal changes. Graefe's Arch Clin Exp Ophthalmol. 2000;238:861-867. doi:10.1007/s004170000192

51. Herbort CP, Jauch A, Othenin-Girard P, Tritten JJ, Fsadni M. Diclofenac drops to treat inflammation after cataract surgery. Acta Ophthalmol Scand. 2000;78:421-424. doi:10.1034/j.1600-0420.2000.078004421.x

52. Laurell CG, Zetterström C. Effects of dexamethasone, diclofenac, or placebo on the inflammatory response after cataract surgery. $\mathrm{Br}$ J Ophthalmol. 2002;86:1380-1384. doi:10.1136/bjo.86.12.1380

53. De Maria M, Coassin M, Mastrofilippo V, Fontana L. Quantitative evaluation of anterior chamber inflammation after phacoemulsification in clinical trials. $J$ Cataract Refract Surg. 2018;44:9. doi:10.1016/j.jcrs.2018.06.043

54. Saito M, Barbazetto IA, Spaide RF. Intravitreal cellular infiltrate imaged as punctate spots by spectral-domain optical coherence tomography in eyes with posterior segment inflammatory disease. Retina. 2013;33:559-565. doi:10.1097/IAE.0b013e31826710ea
55. Keane PA, Karampelas M, Sim DA, et al. Objective measurement of vitreous inflammation using optical coherence tomography. Ophthalmology. 2014;121:1706-1714. doi:10.1016/j.ophtha.2014.03.006

56. Agarwal A, Ashokkumar D, Jacob S, Agarwal A, Saravanan Y. Highspeed optical coherence tomography for imaging anterior chamber inflammatory reaction in uveitis: clinical correlation and grading. $\mathrm{Am}$ J Ophthalmol. 2009;147:413-416.e3. doi:10.1016/j.ajo.2008.09.024

57. Li Y, Lowder C, Zhang X, Huang D. Anterior chamber cell grading by optical coherence tomography. Invest Opthalmol Vis Sci. 2013;54 (1):258. doi:10.1167/iovs.12-10477

58. Igbre AO, Rico MC, Garg SJ. High-speed optical coherence tomography as a reliable adjuvant tool to grade ocular anterior chamber inflammation. Retina. 2014;34:504-508. doi:10.1097/IAE.0b013e31829f73bd

59. Invernizzi A, Marchi S, Aldigeri R, et al. Objective quantification of anterior chamber inflammation: measuring cells and flare by anterior segment optical coherence tomography. Ophthalmology. 2017; 124:1670-1677. doi:10.1016/j.ophtha.2017.05.013

60. Reichel E. Incidence of cystoid macular edema after cataract surgery in patients with and without uveitis using optical coherence tomography: comment. Evidence-Based Ophthalmol. 2010. doi:10.1097/ IEB.0b013e3181c70df4

61. Abbott NJ. Inflammatory mediators and modulation of blood-brain barrier permeability. Cell Mol Neurobiol. 2000;20:131-147. doi:10. 1023/A:1007074420772

62. Pietrowska K, Dmuchowska DA, Krasnicki P, Mariak Z, Kretowski A, Ciborowski M. Analysis of pharmaceuticals and small molecules in aqueous humor. $J$ Pharm Biomed Anal. 2018;159:23-36. doi:10.1016/j.jpba.2018.06.049

63. Chowdhury UR, Madden BJ, Charlesworth MC, Fautsch MP. Proteome analysis of human aqueous humor. Invest Ophthalmol Vis Sci. 2010;51:4921. doi:10.1167/iovs.10-5531

64. Du S, Huang W, Zhang X, Wang J, Wang W, Lam DSC. Multiplex cytokine levels of aqueous humor in acute primary angle-closure patients: fellow eye comparison Glaucoma. BMC Ophthalmol. 2016;16. doi:10.1186/s12886-016-0182-8.

65. Vignali DAA. Multiplexed particle-based flow cytometric assays. $J$ Immunol Methods. 2000;243:243-255. doi:10.1016/S0022-17 59(00)00238-6

66. Liu YC, Setiawan M, Ang M, Yam GHF, Mehta JS. Changes in aqueous oxidative stress, prostaglandins, and cytokines: comparisons of low-energy femtosecond laser-assisted cataract surgery versus conventional phacoemulsification. $J$ Cataract Refract Surg. 2019;45:196-203. doi:10.1016/j.jcrs.2018.09.022
Clinical Ophthalmology

\section{Publish your work in this journal}

Clinical Ophthalmology is an international, peer-reviewed journal covering all subspecialties within ophthalmology. Key topics include: Optometry; Visual science; Pharmacology and drug therapy in eye diseases; Basic Sciences; Primary and Secondary eye care; Patient Safety and Quality of Care Improvements. This journal is indexed on PubMed
Central and CAS, and is the official journal of The Society of Clinical Ophthalmology (SCO). The manuscript management system is completely online and includes a very quick and fair peer-review system, which is all easy to use. Visit http://www.dovepress.com/ testimonials.php to read real quotes from published authors.

\section{Dovepress}

